\title{
Prognostic Significance of Free Psa/ Total Psa Ratio In Predicting Bone Metastases In Patients With Prostate Cancer
}

\section{Semra OZDEMIR ( $\square$ semozdemir@yahoo.com )}

Çanakkale Onsekiz Mart University https://orcid.org/0000-0003-1302-9630

\section{Ahmet Resit ERSAY}

Canakkale Onsekiz Mart Universitesi Tip Fakultesi

\section{Fulya Koc OZTURK}

Canakkale Onsekiz Mart Universitesi Tip Fakultesi

\section{Beril Su OZDEMIR}

santa\&pharma drug

Research article

Keywords: free/total PSA, prostate cancer, bone scintigraphy

Posted Date: August 28th, 2020

DOI: https://doi.org/10.21203/rs.3.rs-60216/v1

License: (a) (i) This work is licensed under a Creative Commons Attribution 4.0 International License.

Read Full License 


\section{Abstract \\ Background}

In this study, we aimed to investigate the prognostic value of free prostate specific antigen/total prostate specific antigen (free PSA/ total PSA) ratio in prediciton of bone metastases in patient with prostate cancer.

\section{Methods}

In total 175 patients with prostate cancer who underwent whole-body bone scintigraphy were included in the study. All selected scintigraphic studies were reprocessed. Free PSA/total PSA ratio, alkaline phosphatase(ALP) values and Gleason scores of patients were recorded.

\section{Results}

The results of our study shows that a moderate correlation between free PSA and ALP values with bone metastases lesion number. In addition, we detected a weak correlation between total PSA value, free PSA/ total PSA ratio and Gleason score with the number of bone metastases lesions in patients with prostate cancer. To predict bone metastases in prostat cancer, only ALP variable was statistically significant and had a high diagnostic value $(A U C=0.907, p=0.004)$. ALP cut off value was $76.50 \mathrm{IU} / \mathrm{L}$, with $\% 80$ sensitivity and \%82.1 specificity. Additionally according to our results free PSA values, total PSA values, free PSA/total PSA ratio and Gleason score values was not considered as a reliable parameter in prostate cancer cases following bone metastasis development.

\section{Conclusion}

According to the results of our study; the free PSA, total PSA, free PSA/total PSA ratio and Gleason score values was not considered as a reliable parameter in the prostate cancer cases follow-up for bone metastasis development. In addition to ALP can predict bone metastases with $80 \%$ sensitivity and $82.1 \%$ specificity at 76.50 cut off value.

\section{Background}

Prostate cancer is the second most commonly diagnosed cancer among men worldwide after lung cancer and ranks fifth for cancer related mortality rates. Definitive prostate cancer diagnosis is made by biopsy, and the patient selection for the biopsy is important to prevent unnecessary diagnosis/treatment. The most important marker used to decide which patient should be considered for biopsy is serum prostate specific antigen (PSA) value. ${ }^{[1-3]}$ However, PSA, which is a glycoprotein produced by prostate tissue, increases not only in prostate cancer but also in many benign diseases such as BPH (benign 
prostate hypertrophy), prostatitis or urinary infections. ${ }^{[4]}$ Also the specificity and positive predictive value of PSA, as a commonly used marker in prostate cancer screening, is low and an exact cut-off value has not been defined $\left({ }^{[5]}\right.$. In clinical routine, the differentiation of BPH and prostate cancer in patients with PSA levels between $4.0 \mathrm{ng} / \mathrm{mL}$ and $10.0 \mathrm{ng} / \mathrm{mL}$ is difficult. ${ }^{[6-7]}$

Because of these limitations, the use of different forms or kinetics of PSA has been recommended. However, recent studies have revealed that no biomarker alone is sufficient in diagnosis and a multivariable diagnostic approach is more eligible. ${ }^{[5,8,9]}$ Various modalities regarding PSA have been introduced to differentiate prostate cancer from other benign prostate diseases, and PSA derivates or isoforms came into use. Nevertheless, due to some disadvantages of these markers, free prostate specific antigen/total prostate specific antigen (free PSA/ total PSA) ratio has become the most frequently used value in clinical practice. $\left({ }^{[9-10]}\right.$ Recently, it has been reported in the literature that free PSA/total PSA ratio is more significant than PSA alone to differentiate prostate cancer and $\mathrm{BPH}$ in patients with serum total PSA levels between 4.0 and $10.0 \mathrm{ng} / \mathrm{mL}^{[11-12]}$

Prostate cancer mainly causes osteoblastic bone metastasis. The number of metastases in bone is important in predicting the response to the therapy and is generally associated with decreased survival rates. ${ }^{[13]}$ Therefore, early diagnosis of bone metastasis is substantial. Bone scintigraphy is frequently used as a non-invasive, inexpensive and easily accessible imaging method to detect bone metastasis. In addition, bone scintigraphy has been recommended in major urology guidelines as an imaging method for bone metastasis screening in medium-to-high risk patient group and symptomatic patients. PSA values, Gleason Score and clinical stage of the lesion have been known to affect the success rate of this method. ${ }^{[14-15]}$ In this study, we aimed to investigate the prognostic significance of free PSA/total PSA ratio, which has been recently reported to be a more sensitive marker in prostate cancer diagnosis, in detecting bone metastasis.

\section{Methods}

\section{Patient group}

In total, 175 male patients with a mean age of $71.36 \pm 8.61$ were included. Study patients were selected retrospectively among patients with prostate cancer who had been sent to Department of Nuclear Medicine, Faculty of Medicine, for whole-body bone scintigraphy between 2016 and 2019. The bone scintigraphy results were evaluated by two nuclear medicine specialists, and the number of bone metastases were recorded. In cases with more than 30 bone metastases, the number of metastases was recorded as 30. In addition to bone scintigraphy, free PSA/total PSA and ALP values measured over the last month were screened retrospectively and recorded along with the age, the date of cancer diagnosis and Gleason scores of the patients.

All patients provided written informed consent. For this study, necessary approvals were received from the local ethics committee ( Protocol number: 2020-07). 


\section{Bone scintigraphy}

All patients were properly prepared for the procedure, and they read and signed the informed consent forms. 15-30 mCi (doses were adjusted to weight) Tc-99m-tagged diphosphonate compounds (MDP or HMDP) were injected to the patients intravenously. 2-3 hours after the injection, whole-body images in the anterior and posterior projections and -if necessary-spot planar images of the suspicious regions were acquired. The whole body bone scintigraphy imaging was realized with a dual-head gamma camera (Infinia; General Electric Medical Systems, Milwaukee, Wisconsin, USA) using image matrix of $1024 \times$ 1024 with speed of $8 \mathrm{~cm} / \mathrm{min}$ and 10 minutes for the each static. Prior surgery and trauma history were carefully taken. Asymmetrical, multiple, focal lesions, especially located in axial skeleton, were evaluated as bone metastasis, and areas of increased activity possibly due to other reasons (e.g., degenerative changes) were recorded as suspected metastatic lesions.

\section{Statistical Analysis}

All data were analyzed using statistical package software SPSS (Statistical Package for Social Sciences) version 20.0. Descriptive data analysis included number, percentage, mean, standard deviation, minimum, maximum values. In analytical data presentation, we assessed the conformity of the variables to the normal distribution using Kolmogorov-Smirnov Normality Test, since more than 50 patients were included in the study. Continuous variables with normal distribution were analyzed by Pearson correlation test, and Spearman correlation test was used to analyze the continuous variables without normal distribution. Cut off, sensitivity and specificity values were determined by ROC Curve Analysis. A value of $p$ (Type 1 error) $<0,05$ was considered as statistically significant.

\section{Results}

The study population of the present study consisted of 175 male patients with prostate cancer who underwent whole body bone scintigraphy to investigate bone metastasis. The mean age of the patients was 71.36 \pm 8.61 years (minimum-maximum: 48.0-88.0). The mean free PSA and total PSA values of the patients were $19.21 \pm 43.02 \mathrm{ng} / \mathrm{ml}$ and $87.84 \pm 299.83 \mathrm{ng} / \mathrm{ml}$, respectively. The mean value of free PSA/total PSA ratio was calculated as $0.026 \pm 0.731$. The mean ALP and Gleason score of the patients were $181.87 \pm 283.46 \mathrm{IU} / \mathrm{L}$ and $7.75 \pm 1.43$, respectively. The demographic and clinical characteristics of the case groups are summarized in Table 1 .

When number of bone metastasis and free PSA value were compared with total PSA, free PSA/total PSA ratio, ALP value, Gleason score, a weak correlation was found between total PSA (rho $=0.315$ ), free PSA/total PSA value (rho=0.367), Gleason score $(r h o=0.382)$ and the number of bone metastatic lesions (Table 2). In addition, our study revealed a moderate correlation between free PSA (0.406), ALP values $(0,539)$ and the number of bone metastasis lesions (Table 2). In terms of detecting bone metastasis in prostate cancer, free PSA value, total PSA value, free PSA/total PSA ratio, ALP value and Gleason score were analyzed using ROC curve analysis and only ALP variable was found to be statistically significant with a high diagnostic value (AUC=0.907, $p=0.004)$. The $76.50 \mathrm{IU} / \mathrm{L}$ cut-off value for ALP variable had a 
sensitivity of $80.0 \%$ and specificity of $82.1 \%$. Our results demonstrated a moderate correlation between bone metastasis and ALP values. Also, free PSA value, total PSA value, free PSA/total PSA ratio and Gleason score were not considered as reliable parameters in cases with bone metastasis associated with prostate cancer in our study(Figure 1) (Table 3).

When ROC analysis of free PSA, total PSA, free PSA/ total PSA ratio, Alp and Gleason scores were used to detect bone metastases in prostate cancer; To detect of bone metastases in prostat cancer, only ALP variable was statistically significant and had a high diagnostic value ( $A U C=0.907, p=0.004)$. ALP cut off value was $76.50 \mathrm{IU} / \mathrm{L}$, with $\% 80$ sensitivity and \%82.1 specificity. Our results show that there is a moderate correlation between bone metastasis and ALP values. On the other hand according to our results free PSA (AUC=0.657, $p=0.269)$, total PSA (AUC=0.661, $p=0.259)$, free PSA/total PSA ratio (AUC=0.521, $p=0.880)$ and Gleason score $(A U C=0.529, p=0.841)$ values was not considered as a reliable parameter in prostate cancer cases following bone metastasis development(Figure1)(Table 3).

\section{Discussion}

In this study, our objective was to investigate the prognostic value of free PSA / total PSA ratio, which has recently been reported to be a more sensitive indicator in the diagnosis of prostate cancer, in the detection of bone metastasis. According to our results, correlation levels we determined between the number of bone metastases detected by the bone scintigraphy (which is used to follow-up patients with prostate cancer) and fPSA, tPSA, free PSA/ total PSA ratio, ALP, Gleason scores were as follows: A weak correlation was found between total PSA (rho $=0.315)$, free PSA / total PSA ratio $(0.367)$ and Gleason score (0.382) with the number of bone metastases lesions in patients with prostate cancer while a moderate correlation was found between free PSA $(0.406)$ and ALP values $(0,539)$ with bone metastases lesion number. As bone scintigraphy is a highly sensitive and specific examination used for to detect bone metastases, the results of our study led us to conclude that free PSA, total PSA, free PSA/ total PSA ratio and Gleason score values was not considered as a reliable parameter in prostate cancer cases following bone metastasis development. On the other hand, the $76.50 \mathrm{IU} / \mathrm{L}$ cut-off value for ALP had a sensitivity of $80.0 \%$ and specificity of $82.1 \%$ for the prediction of bone metastases.

Serum prostate specific antigen (PSA) is currently the most commonly used marker in diagnosis and follow-up. The use of PSA for prostate cancer screening was approved in 1994 by the US Food and Drug Administration. ${ }^{[16-17]}$ However, PSA is not a cancer-specific marker, leading to unnecessary biopsies, especially in the range of $4.0-10.0 \mathrm{ng} / \mathrm{mL}$, defined as the gray zone. In this range, the most commonly used parameter to increase the specificity of PSA is free PSA/total PSA ratio. While $5 \%$ of serum PSA is found to be free, this level decreases in patients with prostate cancer. Therefore, free PSA measurement is used to increase the sensitivity of cancer detection in patients with normal PSA values and to increase specificity in patients with high total PSA $(2.5-10 \mathrm{ng} / \mathrm{mL}) .{ }^{[18-19]}$

Recently, increasing number of reports have demonstrated that free PSA/total PSA ratio can be used for biopsy decision in prostate cancer diagnosis. $\left({ }^{[12,20]}\right.$ In a study including 4955 patients with total PSA 
values between 4 and $10 \mathrm{ng} / \mathrm{ml}$, Erol et al. has determined that a free PSA/total PSA ratio of $<0,10$ has the highest specificity and $>0,30$ has the highest sensitivity in prostate cancer diagnosis. In addition, this study has demonstrated that free PSA/total PSA ratio varies by age. ${ }^{[21]}$

Catalona et al. has reported that free PSA/total PSA ratio significantly decreases in presence of aggressive prostate cancer (Gleason score $\geq 7$, presence of metastasis), and the 0,25 cut-off value for free PSA/total PSA ratio would have a sensitivity of $95 \%$ in prostate cancer diagnosis, and consequently $20 \%$ of the unnecessary biopsies could be prevented. ${ }^{[22]}$ NCCN (The National Comprehensive Cancer Network) guideline recommends using free PSA/total PSA ratio for TRUS-guided prostate biopsy decision in patients without prior biopsy history, with a PSA value of $>3 \mathrm{~g} / \mathrm{ml}$ or high-risk patients with prior negative biopsy results. ${ }^{[23]}$ Similarly, EUA (European Urology Association) guideline reports that free PSA/total PSA ratio can be used to avoid unnecessary biopsies in patients with total PSA values between 2-10 ng/ml. ${ }^{[24]}$ Likewise, Bjork et al. has reported low free PSA/total PSA ratio in male patients with prostate cancer. ${ }^{[25]}$ Free PSA/total PSA ratio, calculated using simultaneous immune determination of both free PSA and total PSA, has been reported to yield better results than PSA or its derivations alone in prostate cancer diagnosis. This ratio is recommended to be used especially in cases with low total PSA levels.

On the other hand, there are articles reporting that free PSA/total PSA ratio is not significant as expected. For example Agnihotri $S$ et al. concluded that the value of $f / t$ PSA in symptomatic men and found a very limited value to improve specificity of total PSA. ${ }^{[26]}$ Moreover, Huyghe E et al. claim that the calculation of the free PSA/ total PSA ratio does not appear to provide any decisional criteria in favour of radical prostatectomy. ${ }^{[27]}$

${ }^{9 \mathrm{~m}}$ Tc-MDPwhole-body bone scintigraphy is a highly sensitive imaging method that has been used for decades to evaluate prostate cancer bone metastasis based on its availability and low cost. A metaanalysis has reported a patient-level sensitivity of $79 \%$ and specificity of $82 \%$ and a lesion-level sensitivity of $59 \%$ and specificity of $75 \% .{ }^{[28,29]} \mathrm{A}$ correlation has been investigated between bone metastasis and PSA level, ALP level and Gleason score, and consequently, correlations at varying levels have been mentioned in the literature. ${ }^{[30-32]}$

Some authors recommended the use of bone scan in symptomatic patients or if alkaline phosphatase levels are $>90 \mathrm{U} / \mathrm{I}^{\left[{ }^{[33]}\right.}$ The authors described correlation between PSA value and both presence and number of metastases with a cutoff value of PSA of $10 \mathrm{ng} / \mathrm{ml}$ for negative bone scans. ${ }^{[34]}$ Otherwise in another recent studies suggest that by considering PSA, a larger proportion of patients with prostate cancer could avoid a staging bone metastases. ${ }^{[35]}$ However, no clear results have been obtained in these articles focusing on determining a cut-off value for the aforementioned parameters in detecting bone metastasis. 
In conclusion according to the results of our study; the free PSA, total PSA, free PSA/total PSA ratio and Gleason score values was not considered as a reliable parameter in prostate cancer cases following bone metastasis development. On the other hand, the $76.50 \mathrm{IU} / \mathrm{L}$ cut-off value for ALP had a sensitivity of $80.0 \%$ and specificity of $82.1 \%$ for the prediction of bone metastases.

\section{Abbreviations}

\section{ALP}

alkaline phosphatase

BPH

benign prostate hypertrophy

free PSA total PSA

free prostate specific antigen/total prostate specific antigen

PSA

prostate specific antigen

\section{Declarations}

\section{Ethics Committee Approval}

Ethics committee approval was received for this study from the local ethics committee of Onsekiz Mart University (Date: 07.05.2020, No:2020-07).

\section{Informed Consent}

Written informed consent was obtained from all patients who participated in this study.

\section{Peer-review}

Externally peer-reviewed.

\section{Conflicts of interest}

The authors have no conflicts of interest to declare.

\section{Financial Disclosure}

The authors declared that this study has received no financial support

\section{Author Contributions}

Concept and Design-SÖ., ARE.; Supervision-SÖ.; Material-FKÖ.; Data Collection and/or Processing-BSÖ., FKÖ; Analysis and/or Interpretation-SÖ., ARE.; Literature Search- SÖ.,BSÖ.; Writing Manuscript-SÖ. 


\section{References}

1-Abdollah F, Dalela D, Haffner MC, Culig Z, Schalken J. The Role of Biomarkers and Genetics in the Diagnosis of Prostate Cancer. Eur Urol Focus 2015 Sep;1(2):99-108.

2-Moradi A, Srinivasan S, Clements J1, Batra J. Beyond the biomarker role: prostate-specific antigen (PSA) in the prostate cancer microenvironment. Cancer Metastasis Rev 2019 Sep;38(3):333-346.

3-Nevo A, Navaratnam A, Andrews P. Prostate cancer and the role of biomarkers. Abdom Radiol (NY) 2019 Nov 13. doi: 10.1007/s00261-019-02305-8. [Epub ahead of print]

4-Bernal-Soriano MC, Parker LA, López-Garrigos M, Hernández-Aguado I, Caballero-Romeu JP, et al. Factors associated with false negative and false positive results of prostate-specific antigen (PSA) and the impact on patient health: Cohort study protocol. Medicine (Baltimore) 2019 Oct;98(40):e17451. doi: 10.1097/MD.0000000000017451.

5-Horwich A, Parker C, de Reijke T, Kataja V; ESMO Guidelines Working Group. Prostate cancer: ESMO Clinical Practice Guidelines for diagnosis, treatment and follow-up. Ann Oncol 2013 Oct;24 Suppl 6:vi10614. doi: 10.1093/annonc/mdt208. Epub 2013 Jun 27.

6-Carroll PR, Vickers AJ. Point/Counterpoint: early detection of prostate cancer: do the benefits outweigh the consequences? J Natl Compr Canc Netw 2014 May;12(5 Suppl):768-71.

7-Kumar N, Yadav S, Kumar S, Saurav K, Prasad V, Vasudeva P. Comparison of percentage free PSA, MRI and Ga PSMA PET scan for diagnosing cancer prostate in men with PSA between 4 and $20 \mathrm{ng} / \mathrm{ml}$. Indian J Urol 2019 Jul-Sep;35(3):202-207.

8-Verma A, St Onge J, Dhillon K, Chorneyko A. PSA density improves prediction of prostate cancer. Can J Urol 2014 Jun;21(3):7312-21.

9-Nordström T, Akre O, Aly M, Grönberg H, Eklund M4. Prostate-specific antigen (PSA) density in the diagnostic algorithm of prostate cancer. Prostate Cancer Prostatic Dis 2018 Apr;21(1):57-63.

10-Wu ZY, Yang C, Luo J, Deng SL, Wu B, Chen M. Establishment of reference intervals for serum [-2]proPSA (p2PSA), \%p2PSA and prostate health index in healthy men. Onco Targets Ther 2019 Aug $13 ; 12: 6453-6460$.

11-Ito K, Yamamoto T, Ohi M, Kurokawa K, Suzuki K, Yamanaka H. Free/total PSA ratio is a powerful predictor of future prostate cancer morbidity in men with initial PSA levels of 4.1 to $10.0 \mathrm{ng} / \mathrm{mL}$. Urology 2003 Apr;61(4):760-4.

12-Caliskan S. Diagnostic efficacy of free prostate-specific antigen/total prostate-specific antigen ratio for the diagnosis of prostate cancer in low concentration $(\leq 4 \mathrm{ng} / \mathrm{ml})$ and intermediate levels of total prostate-specific antigen (4.01-10.0 ng/ml). J Cancer Res Ther 2017 Apr-Jun;13(2):279-283. 
13-Koizumi M, Motegi K, Koyama M, Terauchi T, Yuasa T, Yonese J. Diagnostic performance of a computer-assisted diagnosis system for bone scintigraphy of newly developed skeletal metastasis in prostate cancer patients: search for low-sensitivity subgroups. Ann Nucl Med 2017 Aug;31(7):521-528.

14-Thomsen FB, Westerberg M, Garmo H, Robinson D, Holmberg L, Ulmert HD, Stattin P. Prediction of metastatic prostate cancer by prostate-specific antigen in combination with T stage and Gleason Grade: Nationwide, population-based register study. PLoS One 2020 Jan 29;15(1):e0228447. doi:

10.1371/journal.pone.0228447. eCollection 2020.

15-Valero J, Peleteiro P, Henríquez I, Conde A, Piquer T, Lozano A, et al. Age, Gleason Score, and PSA are important prognostic factors for survival in metastatic castration-resistant prostate cancer. Results of The Uroncor Group (Uro-Oncological Tumors) of the Spanish Society of Radiation Oncology (SEOR). Clin Transl Oncol 2020 Jan 27. doi: 10.1007/s12094-019-02274-w. [Epub ahead of print]

16-Kouriefs C, Sahoyl M, Grange P, Muir G. Prostate specific antigen through the years. Arch Ital Urol Androl 2009 Dec;81(4):195-8.

17-Reed AB, Parekh DJ. Biomarkers for prostate cancer detection. Expert Rev Anticancer Ther 2010 Jan;10(1):103-14. doi: 10.1586/era.09.168.

18-Vezyraki P, Vlachaki A, Baltogiannis D, Batistatou A, Tsampalas S, V Simos Y. Impact of total PSA and percent free PSA in the differentiation of prostate disease: a retrospective comparative study implicating neoplastic and non-neoplastic entities. J BUON 2019 Sep-Oct;24(5):2107-2113.

19-Esfahani M, Ataei N, Panjehpour M. Biomarkers for evaluation of prostate cancer prognosis. Asian Pac J Cancer Prev 2015;16(7):2601-11.

20-Tanguay S, Bégin LR, Elhilali MM, Behlouli H, Karakiewicz PI, Aprikian AG. Comparative evaluation of total PSA, free/total PSA, and complexed PSA in prostate cancer detection. Urology 2002 Feb;59(2):261-5.

21-Erol B, Gulpinar MT, Bozdogan G, Ozkanli S, Onem K, Mungan G, et al. The cutoff level of free/total prostate specific antigen ( $f / t$ PSA) ratios in the diagnosis of prostate cancer: a validation study on a Turkish patient population in different age categories. Kaohsiung J Med Sci 2014 Nov;30(11):545-50. doi: 10.1016/j.kjms.2014.03.008. Epub 2014 Apr 20.

22-Catalona WJ, Partin AW, Slawin KM, Naughton CK, Brawer MK, Flanigan RC, et al. Percentage of free PSA in black versus white men for detection and staging of prostate cancer: a prospective multicenter clinical trial. Urology 2000,55(3):372-6.

23-NCCN Clinical Practice Guidelines in Oncology (NCCN Guidelines)Prostate Cancer. Versión 2.2019; 2019. NCCN org.

24-Mottet N, Bellmunt J, Bolla M, Briers E, Cumberbatch MG, De Santis M, et al. EAU-ESTRO-SIOG Guidelines on Prostate Cancer. Part 1: Screening, Diagnosis, and Local Treatment with Curative Intent. Eur 
Urol 2017 Apr;71(4):618-629.

25-Björk T, Lilja H, Christensson A. The prognostic value of different forms of prostate specific antigen and their ratios in patients with prostate cancer. BJU Int 1999 Dec;84(9):1021-7.

26-Agnihotri S, Mittal RD, Ahmad S, Mandhani A. Free to total serum prostate specific antigen ratio in symptomatic men does not help in differentiating benign from malignant disease of the prostate. Indian J Urol 2014 Jan;30(1):28-32.

27-Huyghe E, Soulie M, Tollon C, Escourrou G, Pontonnier F, Plante P. Value of free PSA/total PSA ratio in therapeutic decisions in the case of a single positive biopsy of the prostate. Prog Urol 1999 Apr;9(2):2817.

28-Sevcenco S, Grubmüller B, Sonneck-Koenne C, Ahmadi Y, Knoll P, Floth A, et al. Bone Scintigraphy in Staging of Newly Diagnosed Prostate Cancer in Regard of Different Risk Groups. Asia Ocean J Nucl Med Biol 2019 Spring;7(2):149-152.

29-Suh $\mathrm{CH}$, Shinagare AB, Westenfield AM, Ramaiya NH, Van den Abbeele AD, Kim KW. Yield of bone scintigraphy for the detection of metastatic disease in treatment-naive prostate cancer: a systematic review and meta-analysis. Clin Radiol 2018 Feb;73(2):158-167.

30-Wei RJ, Li TY, Yang XC, Jia N, Yang XL, Song HB. Serum levels of PSA, ALP, ICTP, and BSP in prostate cancer patients and the significance of ROC curve in the diagnosis of prostate cancer bone metastases.Genet Mol Res 2016 Jun 3;15(2).

31-Ozu C, Nakashima J, Horiguchi Y, Oya M, Ohigashi T, Murai M. Prediction of bone metastases by combination of tartrate-resistant acid phosphatase, alkaline phosphatase and prostate specific antigen in patients with prostate cancer. Int J Urol 2008 May;15(5):419-22.

32-Shepherd KL, Cool P, Cribb G. Prognostic indicators of outcome for patients with skeletal metastases from carcinoma of the prostate.Bone Joint J 2018 Dec;100-B(12):1647-1654.

33-Moslehi M, Cheki M, Salehi-Marzijarani M, Amuchastegui T, Gholamrezanezhad A. Predictors of bone metastasis in pre-treatment staging of asymptomatic treatment-naïve patients with prostate cancer. Rev Esp Med Nucl Imagen Mol 2013 Sep-Oct;32(5):286-9.

34-Singh OP, Yogi V, Redhu P, Ghori HU, Pareek A, Lal N. Role of serum prostate-specific antigen as predictor for bone metastases in newly diagnosed prostate cancer. J Cancer Res Ther 2019Mar;15(Supplement):S39-S41.

35-Al-Ghazo MA, Ghalayini IF, Al-Azab RS, Bani-Hani I, Barham A, Haddad Y. Do all patients with newly diagnosed prostate cancer need staging radionuclide bone scan? A retrospective study. Int Braz J Urol 2010 Nov-Dec;36(6):685-91; discussion 691-2. 


\section{Tables}

Table 1. Shows some demographic and clinical parameters.

\begin{tabular}{|c|c|c|}
\hline \multirow[t]{2}{*}{ Clinical Parameters } & \multicolumn{2}{|l|}{$\begin{array}{l}\text { Patients Cohort } \\
(n=175)\end{array}$} \\
\hline & Mean \pm SD & Min-Max \\
\hline $\begin{array}{l}\text { Age } \\
\text { (years) }\end{array}$ & $71.36 \pm 8.61$ & $48-88$ \\
\hline $\begin{array}{l}\text { Free PSA }(\mathrm{ng} / \mathrm{ml}) \\
(\mathrm{n}=96)\end{array}$ & $19.78 \pm 43.17$ & $0-235$ \\
\hline $\begin{array}{l}\text { Total PSA }(\mathrm{ng} / \mathrm{ml}) \\
(\mathrm{n}=175)\end{array}$ & $87.91 \pm 298.94$ & $0-2934$ \\
\hline $\begin{array}{l}\text { Free/Total PSA } \\
(n=96)\end{array}$ & $0.234 \pm 0.214$ & $0-1.67$ \\
\hline $\begin{array}{l}\text { Alkaline Phosphatase(IU/L) } \\
(\mathrm{n}=57)\end{array}$ & $181.87 \pm 283.46$ & $12.80 \pm 1722$ \\
\hline $\begin{array}{l}\text { Gleason Score } \\
(n=120)\end{array}$ & $7.75 \pm 1.43$ & $4-10$ \\
\hline $\begin{array}{l}\text { Number of Metastatic Foci } \\
(n=175)\end{array}$ & $9.68 \pm 12.12$ & $0-30$ \\
\hline
\end{tabular}

PSA:prostate spesific antigen,; ALP:alkaline phosphatase. 
Table 2. Spearman's correlation coefficients of bone metastases lesion number and some laboratory parameters.

Parameters

Free PSA ( $\mathrm{n}=96)$

Spearman's correlation rho

$\mathrm{p}$

Total PSA(n=175)

Spearman's correlation rho $\mathrm{p}$

Free/Total PSA(n=96)

Spearman's correlation rho $\mathrm{p}$

$\underline{\operatorname{ALP}(\mathrm{n}=57)}$

Spearman's correlation rho $\mathrm{p}$

Gleason Score $(\mathrm{n}=120)$ Spearman's correlation rho $\mathrm{p}$

\section{Bone metastases lesion number}

0.406

$<0.001^{*}$

0.318

$<0.001^{*}$

0.179

$0.082^{*}$

0.539

$<0.001 *$

0.382

$<0.001^{*}$

PSA:prostate spesific antigen; ALP:alkaline phosphatase.

*: Correlation is significant at the 0.05 level (2-tailed)

Table 3. Sensitivity and spesificity percentage of ALP, free PSA, total PSA, gleason score and free/total PSA values.

\begin{tabular}{|c|c|c|c|c|c|c|}
\hline & & $\begin{array}{l}\text { Free PSA } \\
n=96\end{array}$ & $\begin{array}{l}\text { Total PSA } \\
n=175\end{array}$ & $\begin{array}{l}\text { Free/Total PSA } \\
n=96\end{array}$ & $\begin{array}{l}\text { ALP } \\
n=57\end{array}$ & $\begin{array}{l}\text { Gleason } \\
n=120\end{array}$ \\
\hline \multirow{5}{*}{$\begin{array}{l}\text { Bone Metastases } \\
\text { Number }\end{array}$} & $P^{*}$ & 0.269 & 0.259 & 0.880 & 0.004 & 0.841 \\
\hline & AUC & 0.657 & 0.661 & 0.521 & 0.907 & 0.529 \\
\hline & Cut-off & 7.13 & 17.92 & 0,147 & 76.5 & 8.5 \\
\hline & Sensitivity \% & 80 & 60 & 60 & 80 & 40 \\
\hline & Specificity \% & 57.1 & 75 & 67.9 & 82.1 & 50 \\
\hline
\end{tabular}

PSA:prostate spesific antigen; ALP:alkaline phosphatase; AUC: area under a curve.

*: $p<0.05$ 
Figures

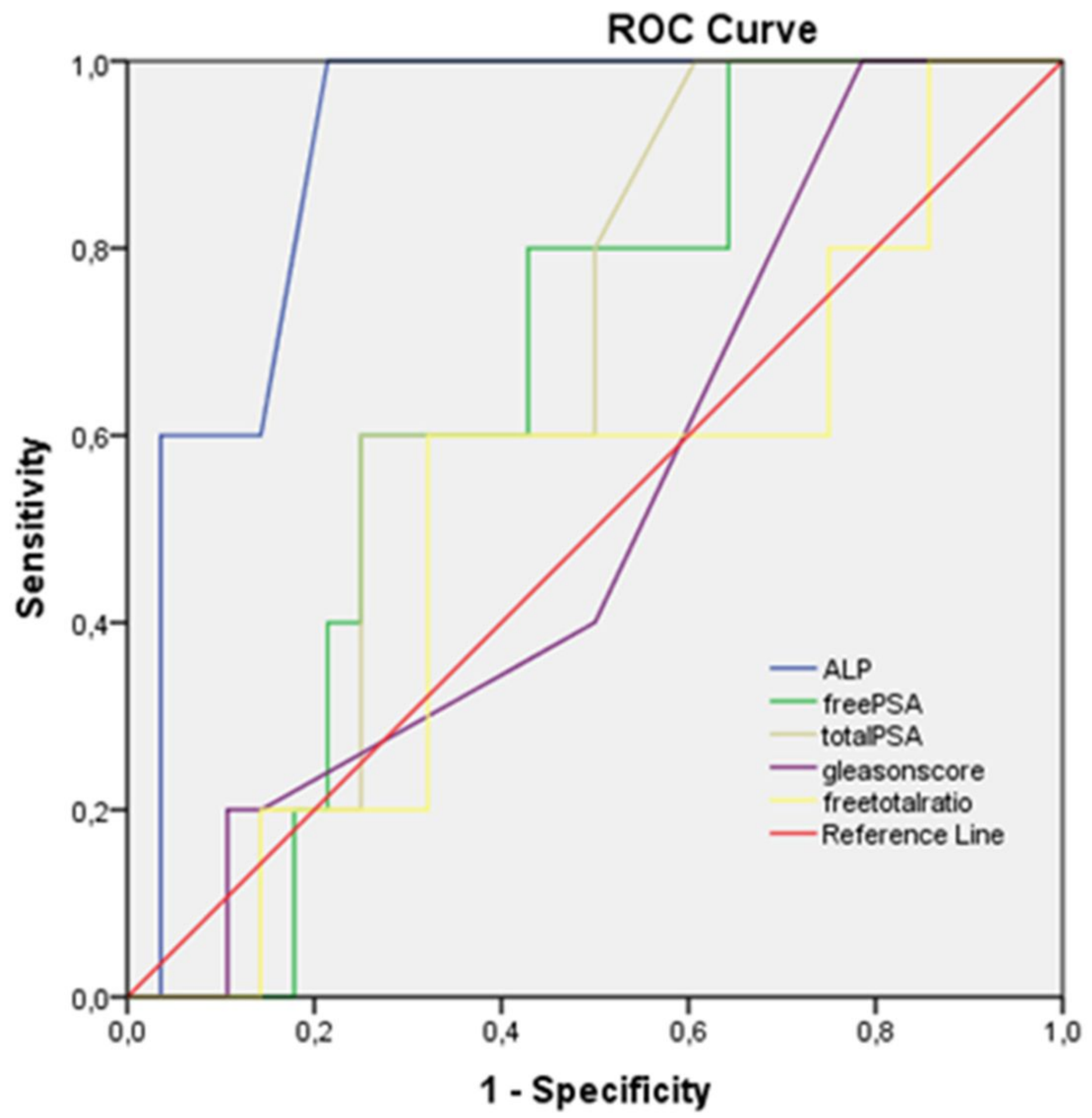

Figure 1

Receiver-operating characteristic curves for ALP, free PSA, total PSA, gleason score, and free/total PSA values. 